\title{
Mother's of Children with Cleft Lip and/or Palate, Perception about Aetiology, Social Reaction and Treatment of Cleft
}

\author{
Akwasi Antwi-Kusi' ${ }^{1}$, William Addisson'1, A. Acheampong Oti ${ }^{1}$, Ama A. Amuasi², \\ Daniel Kwesi Sabbah', Wilson Eva Bernice ${ }^{2}$, Joseph Abu-Sakyi ${ }^{3}$ \\ ${ }^{1}$ Kwame Nkrumah University of Science and Technology, Kumasi, Ghana \\ ${ }^{2}$ Komfo Anokye Teaching Hospital Oral Health Directorate, Kumasi, Ghana \\ ${ }^{3}$ Kwame Nkrumah University of Science and Technology Hospital, Kumasi, Ghana \\ Email: ewzeelah@gmail.com, kmanudecember@gmail.com, aotiacheampong@yahoo.com
}

Received 2 September 2015; accepted 18 October 2015; published 21 October 2015

Copyright (C) 2015 by authors and Scientific Research Publishing Inc.

This work is licensed under the Creative Commons Attribution International License (CC BY). http://creativecommons.org/licenses/by/4.0/

(c) (i) Open Access

\section{Abstract}

Background: Religious, cultural beliefs and demographical differences can have a huge impact in shaping people's reactions and attitudes toward cleft children. Myths and folk beliefs frequently accompany the birth of a child with deformities especially in Africa. Objective: Evaluate cleft mothers with cleft children attending a multidisciplinary cleft clinic at Komfo Anokye Teaching Hospital about their experiences on aetiology, expectation, family reaction and treatment of cleft lip and palate. Methodology: The study design was a cross-sectional study which involved consecutive mothers of cleft lip and palate children reporting to Komfo Anokye Teaching Hospital (KATH) Cleft clinic by using a structured questionnaire. The study period was from January to June 2013. Results: The highest recorded response $(\mathbf{4 7 . 5 0 \% )}$ ) from mothers was that their nuclear families had been supportive. The least recorded nuclear family reaction was indifferent to child's condition (3.70\%). $47.50 \%$ of mothers reported their extended family members had been supportive whereas the least recorded reaction of extended family members $(1.25 \%)$ was avoidant behaviour. 52 Mothers (65\%) answered that they are not mocked by members of the society whereas $28(35 \%)$ answered they were mocked. Conclusion: The above study demonstrates that mother's educational background was low. Some mothers still believe CL/P is caused by evil spirit even though they are in the minority. Most mothers were hopeful that their babies will have a normal life after surgery. There was high level of family support for cleft families.

\section{Keywords}

Cleft, Aetiology, Beliefs, Family, Reaction 


\section{Introduction}

Cleft lip and palate are the commonest congenital abnormalities in children. Incidence of cleft lip and palate not associated with a syndrome varies from region to region. Among Japanese new-borns the incidence is 2.1 in 1000. Among Europeans the incidence is 1 in 1000 new-borns. African Americans have an incidence of 0.3 in 1000 new-borns. In Africa it is about 0.7 per 1000 live births [1].

Giving birth to a child with cleft lip and palate (CL/P) can be emotionally traumatic for parents especially in developing countries where myths and beliefs play a major role in health seeking behaviours. The facial appearance awakens feelings and reactions in the family and other people. Feeding these children in the neonatal period is known to be difficult. Religious and cultural beliefs and demographical differences can have a huge impact in shaping people's reactions and attitudes toward cleft children [2]. Myths and folk beliefs frequently accompany the birth of a child with deformities especially in Africa [2]-[4]. A study in a rural Ghana [5] in 2011 investigated the prevalence of cleft lip and palate in the Ketu South District of Ghana. Respondents were asked about their beliefs and causes of cleft lip and palate condition in their community. Genetic factors and illness from the mother accounted for $17.2 \%$ and $14.1 \%$ of the responses, respectively. However, $40.4 \%$ of respondents confirmed they did not know what caused the cleft.

In 2005 [6], a study in India on the perceptions, expectations, and reactions to cleft lip and palate patients in a native community is presented. The results of the interviews indicated that $64 \%$ of parents did not limit their child's social interaction and were not ashamed to be seen in public. In the above study, regarding causation, the vast majority (84\%) ascribed the cleft to “God's will” and 10\% to sins committed in past lives. Only one parent acknowledged the influence of genetics, although several had a positive family. Concerning their expectations 25 out of 52 were hopeful of better marriage prospects; 16 were hopeful of better educational prospects. This study aims to evaluate cleft mothers with children attending a multidisciplinary cleft clinic at Komfo Anokye Teaching Hospital about their experiences on aetiology, family reaction and treatment of cleft lip and palate

\section{Methodology and Statistics}

The study design was a cross-sectional study which interviewed consecutive mothers with CL/P children reporting at KATH Cleft clinic to help fill a structured questionnaire. The study period was from January to June 2013.

Mothers (80) of cleft lip and palate children reporting at the KATH Cleft Clinic were studied during this study. All mothers consented to be part of the study. The mothers were interviewed as they awaited their turn to see the specialist in the multidisciplinary cleft clinic at KATH. Structured questionnaires (validated) were developed to capture the relevant information including demography, beliefs and knowledge on aetiology of cleft. The language used was English but for those who could neither read nor was write, the questionnaire explained to them using the local language (TWI). Respondents who could not read were assisted to fill the questionnaires. Descriptive analysis for the frequencies of the various responses was done after data had been cleaned and edited using SPSSII. The study was approved by the ethics and research committee of Komfo Anokye teaching hospital.

Results: Study subjects included 80 mothers with CL/P children. This was made up of (39) 48.75\% combined cleft lip and palate; (18) 22.50\% had isolated cleft lip whilst (23) 28.75\% had an isolated cleft palate. Concerning sex distribution, 32 were males and 48 females.

The highest number of cleft (61.25\%) was recorded among mothers between the ages of 21 - 30 years. Educational level of mothers frequently recorded (53.75\%) was those who had attained junior high school education (second cycle education). Those who had attained tertiary school education were those in the minority (5\%).When asked about history of cleft in the family, 76 mothers (representing 95\%) responded in the negative.

The highest recorded response $(47.50 \%)$ from mothers was that the nuclear family had been supportive (Figure 1), followed by extremely supportive (40.0\%) and avoidance (7.50\%). The least recorded reaction was indifference to child's condition (3.70\%).

In this study, $57.50 \%$ of mothers reported their extended family members had been supportive whereas the least recorded reaction of extended family members (1.25\%) was avoidant behaviour. Mothers (65\%) answered that they are not mocked by members of the society. Regarding aetiology, 65\% responded no to superstitious beliefs associated with child's birth and 35\% responded yes. Twelve mothers (15\%) answered no when asked whether they knew condition could be treated before coming to the hospital whereas 68 (85\%) answered yes. 


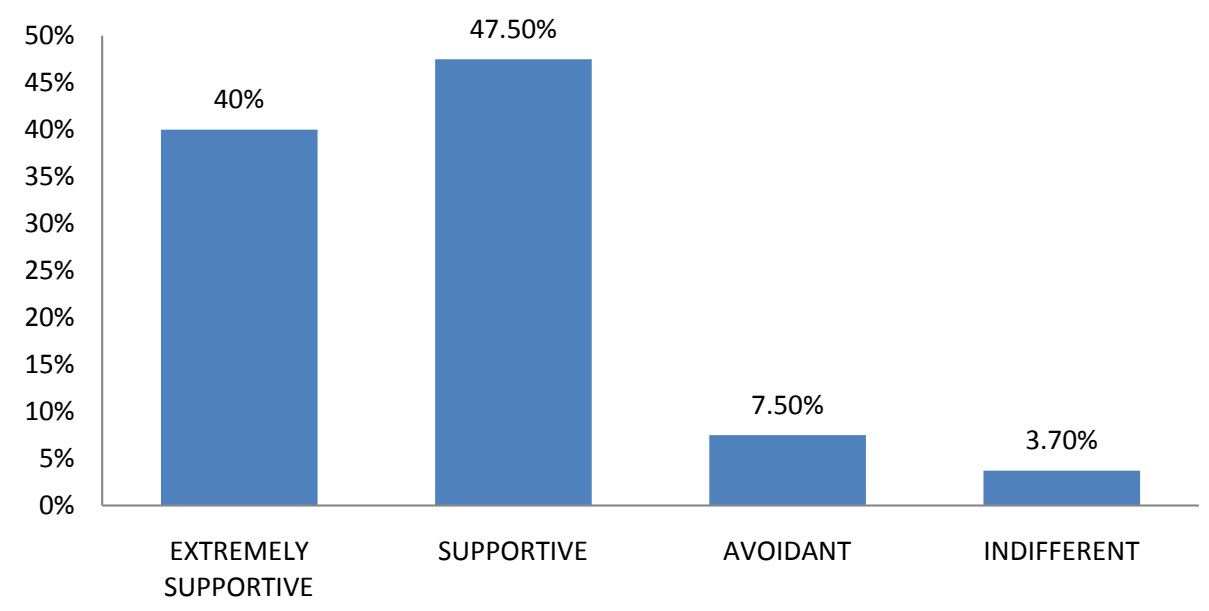

Figure 1. Nuclear family's reaction to child birth.

Mothers who answered yes to the fact that they knew child's condition could be treated were further asked how they thought the treatment will be done before coming to the hospital. Out of the 68 who answered yes 53 (77.94\%) said they knew it will be through surgery; 3 (4.41\%) said it was through drugs prescribed by a doctor and $12(17.65 \%)$ said they had no idea how the treatment will be done. Concerning expectations after surgery 64 mothers (80\%) believed their children will become normal like their age mates, $10(12.5 \%)$ said their children will still have a deformity; 1 (1.25\%) said the condition will become worse whereas 5 mothers (6.25\%) admitted they could not tell what the outcome of the treatment will be.

\section{Discussion}

\subsection{Aetiology and Educational Background}

In this present study, it was clear that most CL/P parent belong to the low socioeconomic class with little or no educational qualification. This finding is similar to most studies especially those from sub-Sahara Africa [7]. The current results about the role of superstition in the aetiology of CL/P were different in an Indian [6] study. In the Indian study, regarding causation, the vast majority (84\%) ascribed the cleft to "God's will” and 10\% to sins committed in past lives compared to only35\% attributing CL/P to superstitions in this study. The difference could be due to the recent radio and television education on $\mathrm{CL} / \mathrm{P}$. The multidisciplinary clinic at KATH has also organised regular surgical outreaches on CL/P. This activity might have created more awareness and thus less belief in superstition as the cause of $\mathrm{CL} / \mathrm{P}$

\subsection{Belief and Myth}

Even though only $35 \%$ of mothers associated the cause of the condition to superstitions, which is lower than that of a recent study from Nigeria [2], it is still important to intensify education especially in the rural communities where empirical evidence support the fact that babies are still being killed because they are believed to be children of the gods and are associated with bad luck to the community. In a related study on the attitudes and beliefs regarding orofacial cleft deformities [4], 15\% of the parents reported the belief of either themselves or the community that something sinful that they had done during pregnancy had caused the defect, such as doing something harmful to another person.

\subsection{Reactions from Family}

It was evident from this study that there was family avoidance of cleft children. This phenomenon was more (7.50\%) from the nuclear family (parents) than the extended family $(1.25 \%)$. This could be due to the fact, the nuclear family reacted that way because of the stigmatisation and disappointment associated with the birth of a cleft child. They have to cope with their child's handicap and the current standardised treatment procedures which start in early infancy. This finding is different from a study where parents did not look upon their child as 
handicapped but as having a congenital defect or "flaw" [3]. But in another study in Uganda, about 91.7\% of the medical staff reported that these children were not accepted in their communities [8]. In this current study, 10 of the mothers admitted to the fact that they were so embarrassed by their babies' condition that they would not bring their babies out least someone sees them and gossips about them. These mothers also reported that they would cry over the baby's condition at the initial stages. They however admitted taking baby out to post natal clinics but ensuring they conceal the affected area. Stigmatisation of CL/P patients and their families is still a major challenge in Africa [9].

Recommendation: We are of the view that more public education especially in the rural communities for people to accept cleft children into their communities. This can be in a form of drama, public lectures, radio and television shows.

\subsection{Expectations}

Majority of mothers were hopeful that the treatment offered at the multidisciplinary cleft clinic will help them have normal babies. This could be due to the fact that, at the cleft clinic most of the old mothers share their experiences with the new mothers. The clinic therefore in our opinion serves as a social therapy for the new mothers.

\section{Conclusion}

The above study demonstrates that mother's educational background was low. Some mothers still believe CL/P is caused by evil spirit even though they are in the minority. Most mothers were hopeful that their babies will have a normal life after surgery. There was high level of family support for cleft families.

\section{References}

[1] Adetayo, O., Ford, R. and Martin, M. (2012) Africa Has Unique and Urgent Barriers to Cleft Care: Lessons from Practitioners at the Pan-African Congress on Cleft Lip and Palate. Pan African Medical Journal, 12, 6-8.

[2] Olasoji, H.O., Ugboko, V.I. and Arotiba, G.T. (2007) Cultural and Religious Components in Nigerian Parents’ Perceptions of the Aetiology of Cleft Lip and Palate: Implications for Treatment and Rehabilitation. British Journal of Oral Maxillofacial Surgery, 45, 302-305. http://dx.doi.org/10.1016/j.bjoms.2006.09.005

[3] Johansson, B. and Ringsberg, K.C. (2004) Parents' Experiences of Having a Child with Cleft Lip and Palate. Journal of Advanced Nursing, 47, 165-173. http://dx.doi.org/10.1111/j.1365-2648.2004.03075.x

[4] Zeytinoglu, S. and Davey, M.P. (2012) It’s A Privilege to Smile: Impact of Cleft Lip Palate on Families. Families, Systems, \& Health, 30, 265-277. http://dx.doi.org/10.1037/a0028961

[5] Agbenorku, P., et al. (2011) A Study of Cleft Lip/Palate in a Community in the South East of Ghana. European Journal of Plastic Surgery, 34, 267-272. http://dx.doi.org/10.1007/s00238-010-0513-6

[6] Weatherley-White, R.C.A., Eiserman, W., Beddoe, M. and Vanderberg, R. (2005) Perceptions, Expectations, and Reactions to Cleft Lip and Palate Surgery in Native Populations: A Pilot Study in Rural India. The Cleft Palate-Craniofacial Journal, 42, 560-564. http://dx.doi.org/10.1597/04-003.1

[7] Donkor, P., Plange-Rhule, G. and Amponsah, E.K. (2007) A Prospective Survey of Patients with Cleft Lip and Palate in Kumasi. West African Journal of Medicine, 26, 14-16. http://dx.doi.org/10.4314/wajm.v26i1.28295

[8] Kesande, T., Muwazi, L.M., Bataringaya, A. and Rwenyonyi, C.M. (2014) Prevalence, Pattern and Perceptions of Cleft Lip and Cleft Palate among Children Born in Two Hospitals in Kisoro District, Uganda. BMC Oral Health, $14,104$. http://dx.doi.org/10.1186/1472-6831-14-104

[9] Mzezewa, S. and Muchemwa, F.C. (2010) Reaction to the Birth of a Child with Cleft Lip or Cleft Palate in Zimbabwe. Tropical Doctor, 40, 138-140. http://dx.doi.org/10.1258/td.2010.090329 